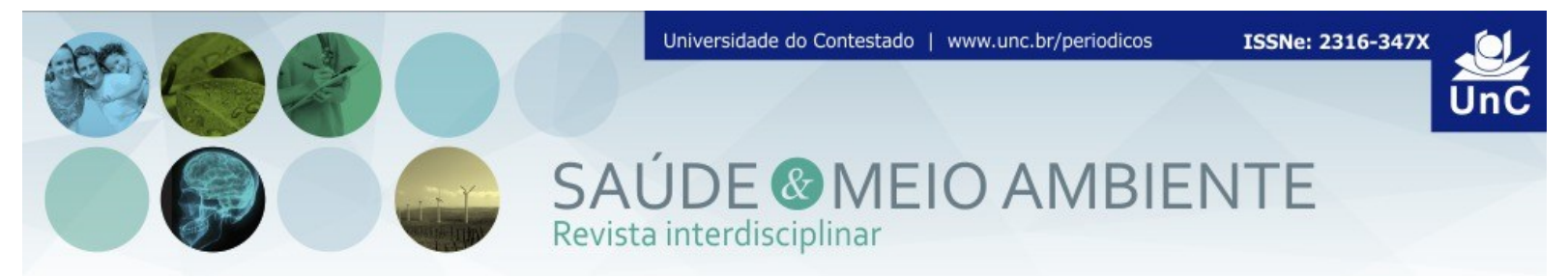

\title{
AVALIAÇÃO MICROBIOLÓGICA DA ÁGUA UTILIZADA PARA CONSUMO HUMANO EM UMA PROPRIEDADE RURAL DE TAIÓ - SC'
}

Débora Ferrari Stolf ${ }^{2}$

\begin{abstract}
RESUMO
No meio rural, a atividade agropecuária além de grande consumidora de água, é também intensa geradora de resíduos. De fato, se o meio agrícola não é contemplado com abastecimento de água potável, ele também não possui coleta e tratamento de esgotos e dejetos. As principais fontes de abastecimento de água no meio rural são os poços rasos e nascentes, fontes bastante susceptíveis à contaminação microbiológica. $O$ objetivo do estudo foi avaliar a qualidade microbiológica da água de uma propriedade rural localizada na cidade de Taió-SC. Os parâmetros microbiológicos analisados foram a presença de coliformes totais e coliformes fecais nas amostras de água em três pontos da rede de abastecimento de água das famílias que residem na propriedade (nascente, caixa reservatória e torneira). As amostras de água foram submetidas a pesquisa de coliformes totais e termotolerantes pela técnica de fermentação em tubos múltiplos e determinação do número mais prováveis (NMP). Os resultados demonstraram que as amostras dos três diferentes pontos analisados apresentaram contaminação por micro-organismos do tipo coliformes fecais. Dentre elas, a que apresentou maior índice de contaminação foi a água da torneira, sugerindo que pode haver contaminação da água durante o seu trajeto desde a nascente até a o local final de consumo. Esse fato provavelmente está relacionado ao longo trajeto percorrido encanamento que conduz a água desde a nascente até a torneira, o qual pode ser facilmente quebrado pelo gado que transita o local e assim entrar em contato com o ar e solo contaminados. De acordo com a Portaria 2.914, de 12 de dezembro de 2011, que dispõe sobre a qualidade microbiológica da água para consumo humano no Brasil, água potável é aquela livre de bactérias do grupo coliformes fecais. Os resultados apresentados neste estudo indicam que a água pesquisada está imprópria para o consumo e deve ser considerada como importante fator de risco à saúde dos seres humanos que a utilizam.
\end{abstract}

Palavras-Chave: Análise microbiológica. Água. Coliformes. Propriedade rural.

\footnotetext{
${ }^{1}$ Trabalho de conclusão de curso- Universidade do Contestado - UnC Canoinhas

${ }^{2}$ Acadêmica do curso de Farmácia da Universidade do Contestado - UnC Canoinhas. Santa Catarina.

Brasil. E-mail: deboravidaluz@hotmail.com

${ }^{3}$ Farmacêutica, Doutora em Neurociências e Professora do curso de Farmácia da Universidade do Contestado - UnC Canoinhas. Santa Catarina. E-mail: simonem@unc.br
} 


\title{
MICROBIOLOGICAL WATER EVALUATION OF RURAL PROPERTY IN TAIO CITY
}

\begin{abstract}
In rural areas, agricultural activity and livestock farming are major consumers of water as well as an intense waste generator. In fact, if the agricultural environment is not contemplated with potable water supply, it also has no collection and treatment of sewage and waste. Wells and water springs are the main sources of water in rural areas and are quite susceptible to microbiological contamination. The objective of the present study was to evaluate the water microbiological quality of the water from a rural property located in the city of Taió-SC. The microbiological parameters analyzed were the presence of total coliforms and fecal coliforms in water samples at three points in the water supply network (source, reservoir box and faucet). The water samples were submitted to total and thermotolerant coliforms by the technique of fermentation in multiple tubes and determination of the most probable number (MPN). The results showed that the samples from the three different points analyzed were contaminated by fecal coliform microorganisms. Among them, the one with the highest contamination index was the water from the faucet, suggesting that there may be contamination of the water during its journey from the source to the final place of consumption. This is probably related to the long distance traveled by the plumbing that leads water from the source to the faucet, which can be easily broken by the cattle that transits the place and thus the water come in contact with the air and only contaminated. According to Portaria 2,914, dated December 12, 2011, which provides for the microbiological quality of water for human consumption in Brazil, potable water is that free of fecal coliform bacteria. The results presented in this study indicate that the water from the rural property is unfit for consumption and should be considered as an important risk factor for their consumers.
\end{abstract}

Keywors: Microbiological analysis. Water. Coliforms. Rural property.

\section{INTRODUÇÃO}

A qualidade microbiológica é uma das características mais importantes da água de consumo, principalmente por que a mesma está diretamente ligada com doenças de origem hídrica. As doenças de veiculação hídrica são aquelas em que a água atua como veículo, transportando o agente infeccioso até a fonte de consumo. Dentre as doenças mais frequentes estão as diarreias e infecções intestinais. causadas principalmente por micro-organismos patogênicos de origem entérica, animal ou humana, transmitidos basicamente pela rota fecal-oral. Estes microorganismos são excretados nas fezes de indivíduos infectados e ingeridos na forma de água ou alimento contaminado por água poluída com fezes (FRANCO e LANDGRAF, 2008). 
O comprometimento da qualidade da água para fins de abastecimento doméstico é decorrente de poluição causada por diferentes fontes, tais como efluentes domésticos, efluentes industriais e deflúvio superficial urbano e agrícola. Outra fonte importante de contaminação das águas refere-se à poluição causada pelas atividades de pecuária em sistemas de confinamento, como a suinocultura, a pecuária de leite e a avicultura (BERTONCINI 2008).

Quanto ao cenário atual do saneamento no meio rural, os dados da Pesquisa Nacional por Amostra de Domicílios (PNAD/2015) demonstram que ainda são intensas as desigualdades no acesso aos serviços de abastecimento de água entre os habitantes das áreas urbanas e rurais. No Brasil, apenas $34,51 \%$ dos domicílios rurais estão ligados à rede de distribuição de água (com ou sem canalização interna), sendo que o restante $(66,6 \%$ das residências) utiliza soluções alternativas e coletivas de abastecimento, como o uso de poços freáticos ou tubulares profundos e a coleta direta das nascentes de água (FUNASA, 2017).

A inexistência das redes de distribuição de água, nas áreas rurais brasileiras, pode ser justificada pela concentração de grandes propriedades, dispersão dos domicílios e facilidade da captação das águas subterrâneas, bem como pela ausência ou insuficiência de sistemas públicos de abastecimento (SILVA; MOREJON; LESS, 2014). As principais fontes de abastecimento de água são os poços rasos e nascentes, fontes bastante susceptíveis à contaminação. Entende-se por nascente o afloramento do lençol freático, que vai dar origem a uma fonte de água de acúmulo (represa) ou cursos d'água (ribeirões e rios). A nascente ideal é aquela que fornece água de boa qualidade, abundante e contínua, próxima do local de uso e de cota topográfica elevada, possibilitando sua distribuição por gravidade, sem gasto de energia. Águas de nascentes podem ser facilmente contaminadas, devido à falta de proteção adequada no local do afloramento ou em suas proximidades. Assim estas áreas devem ser devidamente cercadas, impedindo a entrada de animais domésticos (LEAL, 2012).

A atividade agropecuária além de grande consumidora de água, é também intensa geradora de resíduos. De fato, se o meio agrícola não é contemplado com abastecimento de água potável, ele também não possui coleta e tratamento de esgotos e dejetos. O binômio fossa-poço e a disposição não controlada de dejetos animais em solos é realidade no meio rural brasileiro, ocasionando contaminação ambiental e problemas de saúde pública (BERTONCINI 2008).

A água no meio rural pode ser contaminada no ponto de origem, durante a sua distribuição e, principalmente, nos reservatórios particulares. As causas mais frequentes da contaminação da água nesses reservatórios são a vedação inadequada das caixas d'água e cisternas, e carência de um programa de limpeza e desinfecção regular e periódica (LEAL, 2012).

Há grande importância em buscar o conhecimento da realidade rural, caracterizada por populações com menor acesso às medidas de saneamento e pela presença de atividades agropecuárias altamente impactantes, podendo interferir na qualidade da água dos mananciais (SILVA; MOREJON; LESS, 2014). As consequências mais significativas da carência do saneamento nas áreas rurais são 
a exposição da população rural a doenças oriundas da ingestão de alimentos e de água contaminada pelo esgoto doméstico, como as principais fontes de doenças, entre as quais se destacam a febre tifóide, disenteria, cólera, diarreia, hepatite, leptospirose e giardíase (MERTEN; MINELLA, 2002).

A água potável não deve conter micro-organismos patogênicos e deve estar livre de bactérias indicadoras de contaminação fecal. Os indicadores de contaminação fecal, tradicionalmente aceitos, pertencem a um grupo de bactérias denominadas coliformes. O principal representante desse grupo de bactérias chamase Escherichia coli. O grupo dos coliformes totais é composto por bacilos Gramnegativos não esporulados pertencentes à família Enterobacteriacea, que fermentam lactose com formação de gás quando incubados à $37^{\circ} \mathrm{C}$ por $24-48$ horas e seus principais representantes são as bactérias dos gêneros Escherichia, Enterobacter, Citrobacter e Klebsiella. Já os coliformes termotolerantes são aqueles coliformes totais que apresentam a capacidade de continuar fermentando a lactose, com formação de gás, em temperatura de $44-45^{\circ} \mathrm{C}$ em 24 horas, sendo a bactéria Escherichia coli a principal representante desse grupo. Além disso, essa bactéria pode ser utilizada para indicar uma possível contaminação fecal da água, pois Escherichia coli é um micro-organismo encontrado na microbiota intestinal de animais (FRANCO, LANDGRAF, 2008).

Os padrões apropriados da qualidade da água destinada ao consumo humano proveniente de sistema e solução alternativa de abastecimento de água são estabelecidos no Brasil pela Portaria $\mathrm{n}^{\circ} 2914$ de 12 de Dezembro de 2011 do Ministério da Saúde, a qual define que a água potável deve estar em conformidade com padrão microbiológico, e deve ser livre dos coliformes termotolerantes (BRASIL, 2011).

A maioria das doenças nas áreas rurais podem ser reduzidas consideravelmente desde que a população tenha acesso a água potável. Entretanto, um dos maiores problemas das fontes particulares é a ausência de monitoramento da qualidade da água consumida. De acordo com Zonta et al (2008), o uso de indicadores de qualidade da água torna-se um importante aliado no planejamento de projetos que visam à utilização da água. O número de coliformes termotolerantes em um manancial é um ótimo indicador de contaminação recente, oriunda principalmente de despejo de esgoto doméstico, além da presença de animais próximos às margens do manancial, demonstrando condições higiênico-sanitárias insatisfatórias, sendo um risco para a saúde pública (CUNHA et al., 2010). Também para Leal (2012), a existência de coliformes na água é um importante indicador de que organismos patogênicos podem estar presentes, favorecendo a transmissão de doenças por veiculação hídrica.

Como a qualidade da água é um fator imprescindível à manutenção da saúde humana, o objetivo geral deste estudo foi avaliar a qualidade microbiológica da água consumida em uma propriedade rural de Taió - SC em diferentes pontos, como a nascente, a caixa reservatória e a torneira. Como objetivos específicos, buscou-se detectar a presença de coliformes totais e termotolerantes, e avaliar a qualidade da água como sendo própria ou imprópria para consumo humano com base na Resolução nº 274 (BRASIL, 2011). 


\section{METODOLOGIA}

\section{CARACTERIZAÇÃO DO UNIVERSO DE ESTUDO}

Taió possui $661,5 \mathrm{Km}^{2}$, com uma altitude de $346 \mathrm{~m}$, incorporada ao Alto Vale do Itajaí, uma microrregião situada na área central do Estado de Santa Catarina, que congrega 27 municípios de características homogêneas, que a classificam como o Vale Europeu. Localizada a uma latitude de $27^{\circ} 06^{\prime} 59^{\prime \prime}$ Sul e $49^{\circ} 59^{\prime} 53^{\prime \prime}$ de longitude Oeste, tem um clima mesotérmico úmido - sem estação seca, com uma temperatura média de $15^{\circ} \mathrm{C}$ e umidade relativa do ar em torno de $81 \%$. O relevo é constituído de superfícies planas, onduladas e montanhosas, com fertilidade apta para agricultura, na grande maioria. Possui vasta bacia hidrográfica, captada pelo Rio Itajaí do Oeste, que integra o Rio Itajaí-Açú.

\section{AMOSTRAGEM E COLETA DO MATERIAL}

A principal atividade econômica da propriedade analisada consiste na agropecuária, com a criação de suínos e gado. Na propriedade estão situadas duas casas, sendo que numa delas residem duas pessoas e na outra casa residem quatro pessoas. A água que as pessoas e os animais consomem é coletada de uma nascente e armazenada em reservatório. A partir do reservatório, a água então percorre canos localizados pouco abaixo da terra até chegar aos bebedouros dos animais e também nas torneiras das casas das duas famílias.

Diante do exposto acima, no dia 18 de outubro de 2015 foram selecionados 3 pontos específicos para a coleta de amostras situados ao longo do trecho que a água percorre até chegar ao abastecimento das duas famílias que residem na propriedade. O primeiro ponto foi a nascente, pois é o local primário de onde a água verte de fontes subterrâneas. Também foi selecionado o reservatório uma vez que o mesmo armazena a água que escoa da nascente. Por fim, coletou-se água da torneira, uma vez que a mesma percorre um longo caminho desde o reservatório até a casa para abastecimento. Em cada ponto, foi coletado $1000 \mathrm{~mL}$ de água em um frasco esterilizado, após desinfecção das torneiras com álcool $70 \%$ e drenagem da água durante 2 a 3 minutos. Nas amostras coletadas da nascente e da caixa reservatória o frasco em questão foi introduzido diretamente na água até preencher $1000 \mathrm{~mL}$. 


\section{ANÁLISE MICROBIOLÓGICA}

As amostras coletadas foram enviadas ao Laboratório de Analises Clínicas Vidas, na cidade de Rio do Sul-SC, o qual realizou a análise microbiológica. As amostras foram avaliadas quanto à presença de coliformes totais e coliformes termotolerantes. pela técnica do Número Mais Provável (NMP). O exame se processou por meio de 3 etapas: teste presuntivo, teste confirmativo e o teste de diferenciação para coliformes fecais termotolerantes (MALHEIROS et al., 2009).

Inicialmente as amostras foram diluídas em solução salina peptonada (SSP) $0,1 \%$, na proporção 1:10, 1:100 e 1:1000 numa serie de 5 tubos para cada diluição. Para o teste presuntivo, foram utilizadas três séries de três tubos, com tubo de Durhan, contendo Caldo Lauril Sulfato Triptose (LST), em que foram adicionados 1,0 $\mathrm{mL}$ de cada diluição, e incubados a $35^{\circ} \mathrm{C} / 24-48 \mathrm{~h}$. Aqueles que apresentaram formação de gás no interior do tubo de Durhan e tornaram o meio turvo, foram considerados positivos, portanto seguiram para a próxima etapa (teste confirmativo).

No teste confirmativo, a transferência ocorreu por meio de "swabb" estéril de cultura de todos os tubos positivos de caldo lactosado para tubos contendo caldo lactosado verde brilhante bile (C.L.V.B.B.) $2 \%$, que foram incubados durante 48 horas. A produção de gás, a partir da fermentação da lactose, foi prova confirmada como positiva. A produção de gás nesse meio indica o crescimento de Gram negativos fermentadores de lactose, o que é típico da presença de coliformes. A partir da combinação de números correspondentes aos tubos que apresentaram resultado positivo, verificou-se o Número Mais Provável de acordo com a tabela de NMP conforme os procedimentos básicos de contagem. O valor obtido foi expresso em NMP/100 mL.

Por fim as amostras foram submetidas ao teste para detecção de coliformes termotolerantes (de origem fecal). $O$ teste foi baseado na utilização de um meio seletivo (caldo EC, que contém sais biliares) e incubado em temperatura elevada inibem a maioria dos microrganismos, permitido apenas o crescimento de Echerichia coli e algumas espécies relacionadas. Incubado o caldo EC por $24 \mathrm{~h}$ a $44,5^{\circ} \mathrm{C}$ em banho Maria, e após esse processo foi verificado o número de tubos positivos para saber o NMP de coliformes fecais.

\section{RESULTADOS E DISCUSSÕES}

Todas as amostras analisadas (nascente, caixa reservatória e torneira) apresentaram resultado positivo no teste presuntivo e por isso foram submetidas ao teste confirmativo. Os resultados obtidos para esse teste nas amostras analisadas e as respectivas diluições em termos de NMP de coliformes totais estão demonstrados na Tabela 1. 
Tabela 1 - Número Mais Provável (NMP) de coliformes totais, na água da nascente, caixa reservatória e torneira, de uma propriedade rural na cidade de Taió- SC. Método utilizado pela técnica de números mais prováveis (NMP).

\begin{tabular}{ccccc}
\hline Amostras & $\begin{array}{c}\text { Diluição } \\
\mathbf{1 : 1 0}\end{array}$ & $\begin{array}{c}\text { Diluição } \\
\mathbf{1 : 1 0 0}\end{array}$ & $\begin{array}{c}\text { Diluição } \\
\mathbf{1 : 1 0 0 0}\end{array}$ & NMP/mL \\
\hline Nascente & 5 & 2 & 1 & $5-2-1=60$ \\
$\begin{array}{c}\text { Caixa } \\
\text { reservatória }\end{array}$ & 5 & 2 & 0 & $5-2-0=40$ \\
Torneira & 5 & 4 & 1 & $5-4-1=170$ \\
\hline
\end{tabular}

Foi verificado que as amostras coletadas da nascente, caixa reservatória e torneira na diluição 1:10 apresentaram resultados positivos nos 5 tubos analisados. $\mathrm{Na}$ diluição 1:100 as amostras da nascente e da caixa reservatória apresentaram apenas 2 tubos positivos enquanto que a amostra da torneira apresentou 4 tubos positivos. Na diluição 1:1000 apenas a amostra da nascente e da torneira apresentaram 1 tubo positivo. O resultado final, realizado comparando estes resultados das diferentes diluições na tabela NMP, observou-se que a amostra proveniente da nascente continha $60 \mathrm{NMP} / \mathrm{ml}$, a caixa reservatória $40 \mathrm{NMP} / \mathrm{ml}$ e torneira $170 \mathrm{NMP} / \mathrm{ml}$ para coliformes totais.

As amostras também foram submetidas ao teste para detecção de coliformes termotolerantes (de origem fecal) e os dados obtidos estão representados na Tabela 2.

Tabela 2 - Número Mais Provável (NMP) de coliformes fecais/ termotolerantes, na água da nascente, caixa reservatória e torneira, de uma propriedade rural na cidade de Taió- SC.

\begin{tabular}{ccccc}
\hline Amostras & Diluição & Diluição & Diluição & NMP/mL \\
\hline Nascente & $\mathbf{1 : 1 0}$ & $\mathbf{1 : 1 0 0}$ & $\mathbf{1}: 1000$ & $4-2-0=26$ \\
$\begin{array}{c}\text { Caixa } \\
\text { reservatória }\end{array}$ & 3 & 1 & 0 & $4-2-0=26$ \\
Torneira & 5 & 3 & 0 & $5-3-1=110$ \\
\hline
\end{tabular}

Com relação à amostra coletada da nascente na diluição 1:10, 4 apresentaram resultados positivos. Já a amostra da caixa reservatória nessa mesma diluição apresentou 3 tubos positivos e a amostra da torneira apresentou todos os tubos positivos. Na diluição 1:100 a amostra da nascente apresentou 2 tubos positivos, a caixa reservatória apresentaram 1 tubos positivo e a amostra da torneira apresentou 3 tubos positivos para uma serie de 5 tubos. Na diluição 1:1000 apenas a amostra da torneira apresentaram 1 tubo positivo (Tabela 2). A contagem de tubos positivos em cada diluição e conferência na tabela NMP demonstrou que a amostra proveniente da nascente continha $26 \mathrm{NMP} / \mathrm{ml}$, caixa reservatória $11 \mathrm{NMP} / \mathrm{ml}$ e torneira $110 \mathrm{NMP} / \mathrm{ml}$ para coliformes termotolerantes. 
Um estudo que avaliou a qualidade da água em várias propriedades rurais destinadas ao consumo humano na região oeste de Santa Catarina, também encontrou alto índice de contaminação por coliformes fecais, tanto nas fontes, reservatórios e pontos para consumo humano (MALHEIROS et al., 2009). É comum nessas propriedades o uso de fossas rudimentares (fossa "negra", buraco), que contaminam águas subterrâneas e, obviamente os poços de água, os conhecidos poços "caipiras".

No presente estudo, até mesmo a água proveniente da nascente e da caixa reservatória, que coleta e armazena água da nascente, apresentou contaminação por coliformes fecais, demonstrando assim a susceptibilidade à contaminação desse tipo de nascente. É importante ressaltar, que mesmo sendo consideradas seguras para o consumo in natura, as águas provenientes de poços ou nascentes podem ser contaminadas por diversas fontes, entre eles a percolação de impurezas pelas paredes dos poços (carregadas ou não pela água da chuva) e/ou contaminação direta do lençol freático por um foco de contaminação (fossas irregulares, dejetos de animais) (BERTONCINI, 2008). Ainda, segundo STUKEL et al (1990), esse risco é alto no meio rural, principalmente pela possibilidade de contaminação bacteriana das águas de poços velhos, inadequadamente vedados e próximos a fontes de contaminação. A inexistência, na maioria das nascentes, de todos os fatores de proteção que são preconizados como de grande importância para a preservação da qualidade da água, evidencia a necessidade de um trabalho de orientação às pessoas que utilizam essas águas, com o objetivo de manter sua qualidade (AMARAL et al., 2003). Esta susceptibilidade pode ser ainda mais marcante em períodos de chuva, uma vez que nesse período a percolação é rápida dos microrganismos em direção à água subterrânea. Além disso, a água aproxima-se da superfície do solo, diminuindo sua capacidade filtrante (LEAL, 2012).

O ponto que obteve maior índice de contaminação neste estudo foi a água da torneira, o que sugere que a contaminação ocorreu durante o trajeto da água até o ponto de consumo. Durante o seu trajeto até a torneira da casa, o encanamento passa por valas e pode ser quebradas facilmente pelo gado que transitar no local, ocasionando assim contato com o ar e solo contaminado. Segundo Amaral (2003) o risco de ocorrência de surtos de doenças de veiculação hídrica no meio rural é alto, principalmente em função da possibilidade de contaminação bacteriana de águas que muitas vezes são captadas em poços velhos, inadequadamente vedados $e$ próximos de fontes de contaminação, como fossas e áreas de pastagem ocupadas por animais.

Segundo a Portaria $n^{0}$ 2.914, de 12 de dezembro de 2011 da Agência Nacional da Vigilância Sanitária (ANVISA) - que dispõe sobre os procedimentos de controle e de vigilância da qualidade da água para consumo humano e seu padrão de potabilidade - a água para consumo humano deve ser livre de coliformes totais e termotolerantes. Apesar de ter analisado apenas uma amostra de água dos diferentes pontos, os resultados presentes neste estudo permitiram avaliar de forma preliminar a qualidade microbiológica da água na referida propriedade rural e permitem concluir que todas as amostras dos diferentes locais analisados estão fora dos padrões microbiológicos aceitáveis de potabilidade e por isso encontram-se inapropriadas para o consumo. 
No que se refere à qualidade da água consumida no meio urbano, verificamse esforços das autoridades em implementar ações que visem fornecer à população uma água com boa qualidade, enquanto no meio rural, de um modo geral, essas ações praticamente inexistem (SILVA; LOREJON; LESS, 2014 ). Ainda, a seção IV da portaria $n^{\circ} 2.914$, estabelece que o responsável pelo sistema ou solução alternativa de abastecimento de água para consumo humano deve assegurar que a água fornecida contenha um teor mínimo de cloro residual livre de 0,5 mg/L. Esse fato é relevante porque as famílias abastecidas pela água analisada neste estudo, ao utilizarem água em condições inadequadas para consumo e sem cloração, estarão expostas ao risco de enfermidades veiculadas pela água.

O saneamento ambiental requer a implantação de infraestrutura apropriada e, na maioria dos casos, pelos elevados custos nem sempre se concretiza. Encarregar o próprio consumidor de controlar a qualidade da água é uma postura incorreta, uma vez que o seu conhecimento quanto aos riscos que a água pode oferecer à saúde é praticamente inexistente. Depreende-se, portanto, que um trabalho intensivo deve ser realizado no sentido de efetuar a vigilância da qualidade da água utilizada no meio rural e implementar ações de educação ambiental, a fim de mudar seu comportamento (AMARAL et al, 2003).

\section{CONSIDERAÇÕES FINAIS}

A contaminação fecal encontrada nas amostras de água estudadas deixa clara a importância desse tipo de estudo na avaliação dos riscos à saúde das populações rurais e o impacto ambiental advindo das atividades humanas.

Outro aspecto que deve ser bastante desenvolvido na percepção de populações rurais, ou que utilizem fontes de água que não sejam submetidas ao tratamento clássico, é que as águas subterrâneas e sub-superficiais merecem a mesma preocupação de tratamento que as águas superficiais em locais onde há alta ocupação humana. Por tudo isso, há necessidade de se estabelecer prioridades sanitárias também às populações rurais, uma vez que elas também interferem na qualidade e quantidade dos mananciais que abastecem a área urbana, pela forma como utilizam os produtos agrícolas e cuidam das matas ciliares e nascentes.

A preservação e a recuperação das nascentes de água não são apenas atitudes que satisfazem à legislação ou propiciam a continuidade do aproveitamento das águas para as mais variadas atividades humanas, mas são, acima de tudo, ações concretas em favor da vida, desta e das futuras gerações em nosso planeta. 


\section{REFERÊNCIAS}

AMARAL, L.A et al. Água de consumo humano como fator de risco à saúde em propriedades rurais. Revista de Saúde Pública. v. 37, n. 4, p. 510-514, 2003.

BERTONCINI, E. I. Tratamento de efluentes e reúso da água no meio agrícola. Revista Tecnologia \& Inovação Agropecuária. v. 1, n. 1, p. 152-169, 2008.

BRASIL. Portaria $n^{\circ}$ 2.914, de 12 de dezembro de 2011. Legislação para águas de consumo humano. Diário Oficial da [República Federativa do Brasil], Brasília, DF, 12 dez. 2011. Capítulo V, Anexo I.

CUNHA, A.H. et al. Análise microbiológica da água do rio Itanhém em Teixeira de Freitas-BA. Revista de Biociências, UNITAU. v. 16, n. 2, p. 86-93, 2010.

FRANCO, B. D. G. M; LANDGRAF, M. Microbiologia dos alimentos. São Paulo: Atheneu, 2008.

FUNDAÇÃO NACIONAL DE SAÚDE. Saneamento rural. Disponível em: $<$ http://www.funasa.gov.br/site/engenharia-de-saude-publica-2/saneamento-rural/>. Acesso em: fev de 2017.

MELLO, Luiz Antonio. A onda maldita: como nasceu a Fluminense FM. Niterói: Arte \& Ofício, 1992. Disponível em: <http://www.actech.com.br/aondamaldita/creditos>. Acesso em: 13 out. 1997.

LEAL, J.T.C.P. Água para consumo na propriedade rural. Belo Horizonte: EMATER-MG, 2012. 18 p.

MALHEIROS, P.S. et al. Contaminação bacteriológica de águas subterrâneas da região oeste de Santa Catarina, Brasil. Revista do Instituto Adolfo Lutz. v. 68, n. 2, p. 305-8, 2009.

MERTEN, G.H.; MINELLA, J.P. Qualidade da água em bacias hidrográficas rurais: um desafio atual para a sobrevivência futura. Agroecologia e Desenvolvimento Rural Sustentável. v. 3, n. 4, p. 33-38, 2002.

SILVA, D. F.; MOREJON, C. F. M.; LESS, F. R. Prospecção do panorama do saneamento rural e urbano no Brasil. Revista Eletrônica do Mestrado em Educação Ambiental, 2014.

STUKEL, T. A. et al. A longitudinal study of rainfall and coliform contamination in small community drinking water supplies. Environmental Science and Technology. v. 24, n. 4, p. 571-575, 1990. 
ZONTA, J. H. et al. Qualidade das águas do Rio Alegre, Espírito Santo. Revista Ciência Agronômica, v. 39, n. 1, p. 155-161, 2008.

Artigo recebido em: 02/03/2016

Artigo aprovado em: 01/06/2017 